\title{
Avaliação do desempenho dos serviços de resíduos urbanos em Portugal
}

\section{Performance evaluation of Portuguese solid waste services}

\author{
Pedro Simões \\ M.Sc. Aluno PhD no Centro de Sistemas Urbanos e Regionais (Cesur) do Instituto Superior Técnico da Universidade Técnica de Lisboa
}

Rui Cunha Marques

PhD. Professor do Cesur do Instituto Superior Técnico da Universidade Técnica de Lisboa

\begin{abstract}
Resumo
Os serviços de resíduos urbanos, por funcionarem em regime de monopólio natural, entre outras razões, são caracterizados por reduzidos incentivos à eficiência e inovação. A avaliação do desempenho pode assumir um papel muito relevante para contrariar esta situação. No Portugal Continental, o mercado de resíduos urbanos caracteriza-se por 29 entidades gestoras plurimunicipais do serviço em 'alta' (transporte, tratamento e recolha diferenciada), enquanto o serviço em 'baixa' (recolha indiferenciada) ainda é, na sua maioria, prestado directamente pelos municípios. O presente estudo pretendeu avaliar a eficiência dos operadores em 'alta' abrangendo a totalidade da população portuguesa continental, utilizando uma versão robusta de técnica não-paramétrica de benchmarking de data envelopment analysis (DEA), baseada no conceito de ordem-m. Os resultados revelaram ineficiências significativas, nas quais se destaca a possibilidade de redução dos custos superior a 100 milhões de euros em 2005, caso as entidades gestoras operassem de modo eficiente.
\end{abstract}

Palavras-chave: serviços de resíduos urbanos; Portugal; eficiência; regulação; análise envoltória de dados.

\begin{abstract}
Urban solid waste services usually act as natural monopolies and so, among others reasons, they are characterized by reduced incentives towards efficiency and innovation. The evaluation of performance and, in particular, the application of benchmarking can assume an excellent role to challenge this situation. In Portugal, the market of urban solid waste is characterized by 29 "wholesale" firms (transportation, treatment and separate collection) and hundreds of "retail" utilities (collection). The collection activity is still largely provided directly by the municipalities. The current study intends to evaluate the efficiency of the Portuguese "wholesale" market of solid waste services, encompassing the whole Continental Portuguese population, using the new robust technique of nonparametric benchmarking technique of data envelopment analysis (DEA), based on the concept of order-m. The outcomes depicted significant inefficiency. In the case of efficiently, firms that would have a reduction of costs of more than 100 million euros in 2005 operated.
\end{abstract}

Keywords: urban solid waste services; Portugal; efficiency; regulation; data envelopment analysis.

\section{Introdução}

A produção crescente de resíduos associada ao desenvolvimento das sociedades é um dos principais desafios encarado pelas sociedades modernas. Deste modo, a gestão dos resíduos urbanos constitui um problema importante no domínio da administração local, cuja responsabilidade passa pela recolha e por posterior tratamento e, que tem como uma de suas prioridades, manter as áreas da sua jurisdição em condições de higiene e de estéticas adequadas.

A evolução dos serviços de resíduos urbanos (SRU), associada à sua complexidade, desencadeou, sobretudo nas últimas décadas, grandes reformas, no sector por toda a Europa, maioritariamente originárias por pressões da própria União Europeia (UE). Alguns países, como a Holanda, implementaram decisões importantes neste domínio, inclusivo anteriores a essas reformas.

O contínuo crescimento de produção de resíduos em Portugal, sobretudo a partir dos anos 1990, e o correspondente tratamento inadequado que lhes era destinado (lixeiras), transformando-se em problemas dramáticos, o que levou às autoridades governamentais a lhe darem mais atenção. No entanto, apenas nos anos 1990 do século passado foi desencadeado um conjunto significativo de medidas que permitiram a recuperação de parte substancial do atraso existente,

Endereço para correspondência: Centro de Sistemas Urbanos e Regionais (CESUR) - Instituto Superior Técnico da Universidade Técnica de Lisboa - Avenida Rovisco Pais, 1049-001 - Lisboa, Portugal - Tel: (+351) 21841-8327 - Fax: (+351) 21840-9884 - E-mail: psimoes@civil.ist.utl.pt

Recebido: 19/9/08 - Aceito: 14/1/09 - Reg. ABES: 141/08 
tornando-se mesmo inovador e pioneiro em diversos campos (por exemplo, regulação).

Pressões exteriores, oriundas tanto da UE como dos próprios utilizadores, e a necessidade de um maior controle das contas públicas incentivaram as instituições públicas a avaliarem e desenvolverem a prestação dos SRU, fundados em princípios de economia, eficiência e eficácia.

A elaboração de estudos que visam a avaliação da eficiência do sector público tem-se revelado cada vez mais importante em Portugal, não só devido às consequentes restrições orçamentais, tendo em conta a estrutura de controlo do défice público, mas também aliado à importância que este sector começa a deter na economia.

Neste âmbito, os SRU, por funcionarem em monopólio natural, entre outras razões, denotam reduzidos incentivos à eficiência e inovação. A avaliação do desempenho e, em particular, a aplicação de benchmarking, pode assumir um papel de maior relevância, no sentido de tentar contrariar esta situação. Este estudo aplica a técnica não paramétrica de benchmarking de data envelopment analysis (DEA), usando o recente conceito de ordem-m para determinar a eficiência dos SRU. A DEA usa a programação matemática para medir a eficiência relativa de unidades organizatórias. Basicamente, esta técnica cria uma fronteira, denominada de fronteira eficiente, constituída pelos operadores mais eficientes (best practices), que serve, por sua vez, de comparação para os restantes. Através desta comparação são medidas as ineficiências dos SRU.

O estimador de ordem-m (CAZALS; FLORENS; SIMAR, 2002), além de se comportar de modo robusto a valores extremos e ao erro, impõe menores assumpções sobre a forma da superfície de produção do que a DEA, requerendo nesse caso, para um maior número de inputs e outputs, muito menos dados, para obter estimativas de ineficiência, com significância, do que os estimadores de fronteira determinísticos, como a DEA.

A principal ideia subjacente a esta técnica prende-se com a estimação da fronteira eficiente não ser feita pela envolvência de toda a amostra, mas apenas por amostragem repetida de determinadas entidades gestoras ( $m$ vezes com amostra de tamanho $n$ ) e a construção de médias das amostras, até ao ponto onde a fronteira hipotética resultante tem a precisão desejada. Desta forma, o efeito dos outliers pode ser reduzido substancialmente, mesmo tratando-se de uma amostra de tamanho moderado, conferindo a robustez pretendida.

\section{0 modelo regulatório do sector dos resíduos em Portugal}

\section{Organização do sector}

O mercado dos resíduos encontra-se segmentado em sistemas em "alta", "baixa" e recolha selectiva. É possível, desta forma, definir sistema em "baixa" (retalho), como o processo de gestão da recolha dos resíduos ao encargo dos municípios desde os locais de deposição, às estações de transferência, ou, na ausência destas, às estações de tratamento e de valorização. O sistema em "alta" (grossista) restringe-se às operações de gestão que têm início nas estações de transferência até a deposição final em aterro ou outro destino de tratamento e cabe, usualmente, às entidades gestoras a responsabilidade deste processo. Em relação às embalagens e resíduos de embalagens, designado por mercado terciário, existe um circuito particular denominado de Sistema Integrado de Gestão de Resíduos de Embalagens (Sigre), mais conhecido por Sociedade Ponto Verde (SPV), que garante a retoma, valorização e reciclagem de resíduos de embalagem não reutilizáveis.

O mercado terciário em Portugal baseia-se na responsabilização da SPV pela gestão e destino final dos resíduos produzidos por embaladores/importadores, principais responsáveis pelas embalagens no mercado, e, como prestação do serviço, estes asseguram o seu financiamento. O papel das autarquias neste sistema limita-se a conduzir as embalagens usadas, oriundas da recolha selectiva e a triagem, para a SPV.

Em Portugal Continental existem 29 sistemas plurimunicipais responsáveis pela gestão de resíduos em "alta". Destes, 15 são concessões e pertencem ao segmento multimunicipal, dos quais 13 são controlados pela EGF (sub-holding do Grupo Águas de Portugal), e 14 são sistemas intermunicipais. No âmbito da gestão dos SRU em "baixa", concretamente a recolha indiferenciada de resíduos e/ou limpeza urbana, apesar da crescente participação do sector privado, são actividades usualmente praticadas pelo próprio município ou por terceiras entidades por meio de contratos de prestação de serviços. Actualmente, existem 245 operadores, variando entre sistemas intermunicipais e gestão directa do município.

\section{Regulação do sector}

\section{Introdução}

Em Portugal existe uma entidade reguladora, o Instituto Regulador de Águas e Resíduos (Irar), dedicada ao sector dos resíduos. Esta circunstância é pouco usual, pelo menos, no cenário europeu. O Irar tem como principal preocupação a protecção dos interesses dos utilizadores dos SRU, promovendo a qualidade de serviço prestada pelas entidades gestoras e garantindo o equilíbrio dos tarifários praticados, conotados a princípios de essencialidade, indispensabilidade, universalidade, equidade, fiabilidade e de custo-eficácia.

No desempenho das suas funções, o Irar adoptou como ferramenta principal a publicação e comparação periódica (benchmarking) de um conjunto de indicadores de gestão (regulação sunshine), que verificouse ser um instrumento poderoso e eficaz no fornecimento de incentivos de desempenho, suscitando competição (virtual) entre as várias empresas envolvidas através da sua comparação (MARQUES, 2006B). 


\section{Irar}

\section{Atribuições}

O Irar tem na regulamentação, orientação e fiscalização da concepção; execução, gestão e exploração dos sistemas multimunicipais e municipais, bem como a actividade das respectivas entidades gestoras, suas atribuições principais. Para além destas missões, ele garante a regulação dos respectivos sectores e o equilíbrio entre a sustentabilidade económica dos sistemas e a qualidade dos serviços, de forma a salvaguardar os interesses e direitos dos cidadãos. Ademais, compete ao Irar promover a normalização técnica do sector e, por último, estabelecer relações com outras instituições congéneres nacionais e internacionais, de forma a melhorar a sua actividade. Todavia, existem factores limitativos da desenvoltura do Irar, como a inexistência de sanções previstas a entidades gestoras concessionárias com mau desempenho pontual e sistemático e também pelo facto de os operadores do mercado nos SRU não concessionados não se encontrarem sujeitos à regulação do Irar, pelo menos até à data (setembro de 2008). Os operadores concessionados, designadamente as entidades gestoras de sistemas multimunicipais e municipais, estão sujeitos à regulação económica com diferentes níveis de intervenção e a avaliação de desempenho anual.

\section{Regulação sunshine}

O Irar adoptou a regulação sunshine como um dos seus instrumentos principais de regulação. Para esse efeito, o Irar reúne num relatório anual os resultados do desempenho das entidades gestoras. A elaboração desse documento inclui uma avaliação conjunta do desempenho, na qual são efectuadas comparações entre as entidades gestoras e uma avaliação individual do desempenho de cada operador qualitativa e quantitativamente.

A consciencialização da actuação das entidades gestoras pretendida pelo Irar é obtida por pressão dos consumidores e dos cidadãos em geral, por seus grupos de defesa e representação, como os media, a classe política (Governo e partidos políticos) e as Organizações Não Governamentais.

O fraco desempenho das entidades gestoras tem como consequência o seu constrangimento perante os diversos stakeholders e, por conseguinte, estas terão maior propensão a corrigir os desvios manifestados. Embora este método não fixe tarifas e o seu poder coercivo seja limitado, a exposição e a discussão pública do comportamento do regulado desencadeia efeitos bastante positivos, introduzindo competitividade entre as entidades reguladas e conduzindo a um aumento progressivo da performance no sector (MARQUES, 2005).

\section{Qualidade do serviço}

Um dos principais objectivos (e resultados) da regulação sunshine consiste na melhoria da qualidade do serviço. O Irar recorre para este efeito a um conjunto de indicadores de desempenho que publica no relatório anual referido. Estes indicadores medem a eficiência e eficácia dos operadores relativas a aspectos específicos da actividade desenvolvida ou do comportamento do sistema.

Os indicadores de desempenho nos SRU reflectem, de forma isolada ou combinada entre si, as condições de funcionamento dos sistemas em análise (TEIXEIRA; NEVES, 2007), apesar de, a priori, se saber que ao analisar apenas um indicador se trata de uma visão parcial da realidade da gestão (medida parcial de produtividade). Consequentemente, o Irar implementou um conjunto de 20 indicadores de desempenho divididos em três grupos, nomeadamente, os relativos à defesa dos interesses dos utilizadores, à sustentabilidade da entidade gestora e ambiental.

Por fim, o Irar, em adição ao que lhe compete e através do seu relatório anual, se avalia e emite algumas observações relativas ao resultado de cada indicador por operador. Esta avaliação é exercida segundo um sistema de classificação que compara o valor obtido com o correspondente valor de referência. Os valores de referência são valores óptimos, ou próximo disso, que o regulador considera como razoáveis de atingir para os operadores regulados. No entanto, como o próprio nome do valor de referência indica, estes valores não podem ser analisados per si e descontextualizados. Deste modo, o Irar classifica qualitativamente o desempenho de cada operador, levando em conta a qualidade do serviço prestado, se insatisfatória, mediana ou boa, mediante a discrepância entre o resultado obtido pelo indicador e o intervalo de valores de referência. O Irar publica os resultados, hierarquizando-os, por indicador de desempenho. Além disso explana, por operador, os resultados obtidos do cálculo dos indicadores de desempenho, quantificando e classificando a qualidade de serviço em insatisfatória, mediana ou boa, atribuindo-lhe uma bola vermelha, amarela ou verde, respectivamente. O Quadro 1 expõe não só os indicadores de desempenho utilizados pelo Irar, mas também a evolução dos mesmos desde o início da sua implementação.

Tarifas e regulação económica

A regulação económica é tomada como a mais importante forma de regulação dos comportamentos permitidos às entidades gestoras, tendo em conta que os preços de monopólio tendem a ser mais elevados do que os preços resultantes de mercados concorrenciais.

As atribuições do Irar, no que concerne ao estabelecimento de preços e tarifas, são analisadas mediante a gestão e organização, a saber, gestão por administração autárquica ou indirecta (serviços municipais, serviços municipalizados e empresas municipais) e por gestão delegada (sistemas municipais e sistemas multimunicipais).

Em relação aos serviços municipais, aos serviços municipalizados e aos diferentes modelos de empresas municipais, o Irar não tem qualquer tipo de atribuição neste domínio. Os sistemas tarifários são aprovados pelo respectivo órgão social autárquico competente, neste caso a Assembleia Municipal. 
Em Portugal Continental, os sistemas tarifários implementados pelos municípios apresentam grande variabilidade, não só pelo modo como são cobrados, mas também pelos correspondentes montantes. Actualmente, a gestão dos SRU encontra-se numa indubitável insustentabilidade financeira, gerada pela escassa cobertura dos sistemas tarifários em relação aos seus custos reais.

Os preços praticados são estabelecidos mediante uma parcela fixa e/ou uma parcela variável, variando consoante o município. A remuneração do serviço é, usualmente, discriminada na factura da água. Porém, também pode ser estabelecida em função da frequência da remoção, das características do município (por exemplo, área), do sistema de remoção (por exemplo, sistema de remoção porta-a-porta ou por pontos) ou das características dos fogos.

Nos sistemas municipais concessionados, as tarifas são definidas no contrato de concessão outorgado entre o concedente (Câmara Municipal ou Associação de Municípios) e o concessionário. A fixação de tarifas é estabelecida na proposta para concurso, tendo em conta o enquadramento legal. O Irar não pode interferir directamente na fixação da tarifa, a não ser que o equilíbrio económico-financeiro da concessão seja colocado em causa, por motivos não previstos, quando da realização do contrato, situação à qual, o Irar pode ser chamado a se pronunciar.

Nos sistemas multimunicipais o Irar tem outros tipos de poderes, sendo solicitado para emitir pareceres sobre os sistemas

Quadro 1 - Indicadores de desempenho para a gestão de resíduos urbanos (IRAR, 2006)

\begin{tabular}{|c|c|c|c|}
\hline Indicadores de desempenho & 2004 & 2005 & 2006 \\
\hline \multicolumn{4}{|l|}{ Defesa dos interesses dos utilizadores } \\
\hline Cobertura do serviço (\%) & 100 & 100 & 100 \\
\hline Cobertura da recolha selectiva (\%) & 67 & 77 & $79 *$ \\
\hline Preço médio do serviço (€/t) & 26,6 & 24,6 & 26,6 \\
\hline Resposta a reclamações escritas & 41 & 89 & 92 \\
\hline \multicolumn{4}{|l|}{ Sustentabilidade da entidade gestora } \\
\hline Rácio de cobertura dos custos operacionais (-) & 1,5 & 1,58 & 1,65 \\
\hline Custos operacionais unitários (€/ton) & 21,6 & 22,6 & 25,36 \\
\hline Rácio de solvabilidade (-) & 0,19 & 0,51 & 0,55 \\
\hline Reciclagem (\%) & 4,1 & 6,0 & 6,4 \\
\hline Valorização orgânica (\%) & 2,8 & 2,9 & 1,5 \\
\hline Incineração (\%) & 66,1 & 82 & 79 \\
\hline Deposição em aterro (\%) & 74,5 & 89,6 & 88 \\
\hline $\begin{array}{l}\text { Utilização da capacidade de encaixe } \\
\text { anual de aterro (\%) }\end{array}$ & 128 & 116 & 121 \\
\hline $\begin{array}{l}\text { Avarias em equipamento pesado } \\
\text { ( } \mathrm{n}-1 / 10^{3} \text { ton/ano) }\end{array}$ & 0,17 & 0,16 & 0,14 \\
\hline Caracterização dos resíduos (-) & 1,5 & 2,8 & 2,3 \\
\hline Recursos humanos ( $\mathrm{n}$ \% $/ 10^{3}$ ton/ano) & 0,35 & 0,46 & 0,49 \\
\hline \multicolumn{4}{|l|}{ Sustentabilidade ambiental } \\
\hline Análises realizadas aos lixiviados (\%) & 90 & 80 & 96 \\
\hline Qualidade dos lixiviados após tratamento (\%) & 86 & 79 & 87 \\
\hline Utilização de recursos energéticos (kWh/t) & $-66,5$ & $-90,4$ & $-87,9$ \\
\hline Qualidade das águas subterrâneas (\%) & 84 & 97 & 90 \\
\hline Qualidade das emissões para o ar (\%) & 99,8 & 99,5 & 100 \\
\hline
\end{tabular}

tarifários propostos, apoiando-se num programa de investimentos pré-definido à data da realização do contrato de concessão e revisto periodicamente, sobre o relatório anual das empresas e o respectivo orçamento,

A formulação de definição do sistema tarifário proposto nos contratos de concessão dos sistemas multimunicipais consiste numa metodologia híbrida, tendo sido assente no método de regulação por taxa de remuneração estabelecido contratualmente e introduzindo-lhe um mecanismo de repartição de ganhos de produtividade à cabeça. Desta forma, tomando como base os contratos de concessão já outorgados, a taxa de remuneração é fixada pelo concedente com o tributo de TBA $+3 \%$. A TBA representa a taxa base anual, exógena à empresa, ao regulador e ao sector regulado (progressivamente substituída pela Euribor), e o valor de 3\% constitui o risco associado à exploração do empreendimento.

A taxa de remuneração, por conseguinte, só pode ser alterada se ocorrer variação da TBA ou se for revisto o prémio de risco. $O$ valor da taxa incide sobre o capital próprio e não sobre uma parcela do activo que se aceita remunerar. Um aspecto final, que individualiza a metodologia adoptada em Portugal, consiste no estabelecimento de uma cláusula nos contratos de concessão que prevê que as empresas possam reter 50\% dos ganhos de produtividade verificados, ou seja, da diferença entre o custo médio previsto no orçamento anual e o custo médio efectivamente verificado. Esta disposição é promotora e funciona como incentivo da eficiência e da inovação, inserindo uma nuance do método da regulação por limite de preços no método de regulação por taxa de remuneração adoptado.

Obrigações de serviço público

Os serviços de interesse económico geral envolvem actividades que

satisfazem necessidades básicas de natureza económica à generalidade dos cidadãos e cuja existência seja essencial à vida, à saúde ou à participação social (MARQUES, 2005).

Envolvem, inter alia, os sectores dos transportes, os serviços postais, a energia ou qualquer outro serviço público de natureza económica submetido a "obrigações de serviço público", como é o caso dos SRU. Estas obrigações de serviço público restringemse aos requisitos estabelecidos pelas autoridades públicas a quem presta um dado serviço, com o objectivo de satisfazer certos princípios de interesse público, inter alia, o serviço universal, a continuidade, a qualidade do serviço, a acessibilidade de preços e a protecção do utilizador.

Em Portugal, esta matéria, no âmbito dos resíduos, foi apenas, recentemente, contemplada, através da lei 12/2008, de 26 de fevereiro, integrando estes princípios na lei. 


\section{Comparação com outros países}

Confrontando o modelo organizacional e regulatório português do sector dos resíduos com outros modelos europeus, tais como Espanha, Holanda e Inglaterra, ao nível da sua organização e sustentabilidade e analisando os formatos de gestão existentes (formas organizatórias e participação do sector privado), o panorama regulatório existente e, em particular, o estabelecimento de preços, as obrigações de serviço público e a qualidade de serviço fornecida em cada país, denotaram-se algumas diferenças importantes.

A ausência de entidades reguladoras dedicadas ao sector de resíduos, ao nível europeu, não revela a priori que os seus utilizadores estejam mais vulneráveis aos condicionalismos de operadores monopolistas, caracterizados por escassos incentivos à eficiência e inovação, pois existem governos, como o holandês, que detêm um papel bastante presente e interventivo no âmbito da supervisão do sector (por exemplo, incutindo no utilizador o conceito pay-as-you-throw, fomentando a auto-sustentabilidade que actualmente caracteriza o mercado dos resíduos).

$\mathrm{Na}$ Inglaterra, o objectivo do fornecimento dos SRU ao menor custo possível conduziu a um número muito elevado de concursos públicos de outsourcing, arrastando o sector para um ciclo vicioso. Este ciclo culminou com o sector em enorme competitividade e com rendimentos tão reduzidos para os operadores, que se repercutiram em défices de qualidade de serviço ou, em casos mais gravosos, na inviabilidade de prestação do serviço. O Governo Central ao deparar-se com tal conjuntura implementou o regime best value, substituindo o concurso público compulsório, como forma de recuperar a qualidade de serviço e manter o value for money.

$\mathrm{Na}$ Espanha, com a abertura aos operadores privados do sector dos resíduos, foram criadas condições para o desenvolvimento de vários "campeões" nacionais. Se os efeitos de escala podem conduzir a custos reduzidos, prestados por estes players, a desregulamentação substancial existente no sector e, em particular no momento de acesso ao mercado, podem comprometer a protecção e os interesses dos utilizadores deste serviço de interesse económico geral.

\section{Revisão da literatura sobre desempenho dos SRU}

A avaliação do desempenho dos SRU, a confrontação entre a gestão pública e privada e o modelo de estrutura do sector de mercado (integração horizontal ou desverticalização) mais eficiente têm sido as principais temáticas desenvolvidas nos estudos de eficiência no domínio do sector dos resíduos.

A questão da gestão pública versus privada, tendo em conta os inúmeros estudos elaborados, tornou-se um eterno busílis, devido ao facto de terem sido produzidos muitos estudos, muito devido às conclusões divergentes, em parte, geradas pela amostra e técnica adoptadas.

As técnicas adoptadas para determinar a eficiência são escalonadas frequentemente em paramétricas (sobretudo fronteiras estocásticas) e não paramétricas (principalmente DEA). Os estudos de eficiência dos SRU recolhidos na bibliografia contabilizam um total de 55, divididos em estudos que utilizam métodos não paramétricos (18) e métodos paramétricos (37). Nos métodos não paramétricos não estão incluídos trabalhos que empregam medidas parciais de produtividade. Não obstante o número detectado na bibliografia desta última técnica seja muito reduzido, crê-se que, pela sua simplicidade e fácil compreensão, a mesma seja a mais aplicada na avaliação do desempenho ainda que essencialmente pelas entidades gestoras.

No que concerne à técnica DEA e fronteiras estocásticas (e determinísticas), apesar do maior número de trabalhos ser desenvolvido por académicos, existem também diversos reguladores e organismos governamentais que aplicam este tipo de metodologias (Espanha, Austrália, etc.). Muitos estudos que surgem na literatura dizem respeito à análise do desempenho dos municípios como organizações, incluindo também no seu âmbito, a actividade referente aos resíduos, entre as outras que são prestadas.

Subjacente à natureza da actividade de prestação dos SRU observa-se uma maior importância de determinados inputs e outputs em detrimento de outros. Para os métodos não paramétricos, adoptados neste estudo, salientam-se, como as principais variáveis utilizadas relativas aos inputs, o número de trabalhadores e o custo total de serviço (custos de operação e manutenção, OPEX, mais os custos de capital, CAPEX). Os outputs mais adoptados são a quantidade de resíduos recolhidos e o número de utentes dos SRU. No que diz respeito aos factores explanatórios ressalva-se a distância ao aterro e a densidade populacional como os mais utilizados.

Nos 18 estudos referidos, por exemplo, Vilardell e Riera (1989), Distexhe (1993), Bosch, Pedraja e Suárez (2001), Benito, Bastida e García (2005) e Sanchez (2006) utilizam a técnica DEA, e destacam-se três trabalhos desenvolvidos que procuram estudar a influência da eficiência de escala comparando em detalhe os resultados dos modelos com rendimentos constantes à escala (RCE) com os relativos aos rendimentos variáveis à escala (RVE). Dos restantes, dez trabalhos consideram somente RCE e os outros cinco RVE.

No domínio da orientação dos modelos adoptados, 12 dos 18 estudos consideram modelos orientados e seis modelos não orientados. Relativamente à natureza da orientação, existe um equilíbrio entre os trabalhos desenvolvidos mediante a vertente de maximização de output e os trabalhos elaborados, tendo em conta a minimização de input, nomeadamente seis estudos realizados para cada vertente. 


\section{Avaliação do desempenho dos SRU portugueses}

\section{Metodologia}

A DEA é uma metodologia de fronteira não paramétrica, que emprega a programação matemática para medir a eficiência relativa de unidades organizatórias, as quais apresentam um conjunto homogéneo de inputs e outputs. A sua elevada aplicabilidade tem origem nas suas várias vantagens (MARQUES, 2006A), designadamente, pela identificação das boas práticas (best practices) que podem ser transpostas e seguidas por outros operadores; na determinação da dimensão óptima dos operadores; na estimativa dos ganhos potenciais de eficiência (relativas à redução dos factores de produção ou da expansão dos resultados); na obtenção das taxas marginais de substituição entre os factores de produção; no cálculo da variação da produtividade ao longo do tempo de cada operador; na identificação dos operadores mais eficientes em cada ponto no tempo e na determinação da estrutura organizacional mais eficiente (por exemplo, público versus privado ou verticalização versus unbundling).

A eficiência técnica, assumindo valores entre 0 e 1, explana a capacidade de cada operador em despender um mínimo de inputs para um dado nível de outputs ou vice-versa. O operador eficiente, localizado na fronteira determinada pela DEA, é caracterizado pelo valor de eficiência técnica igual a 1 .

A eficiência alocativa traduz a capacidade de cada operador empregar uma combinação de inputs e de outputs que, dados os seus preços, minimizem o custo de produção. Ao produto da eficiência alocativa pela eficiência técnica denomina-se de eficiência económica que representa a redução máxima de inputs para uma dada produção de outputs ou vice-versa (a máxima expansão de outputs para uma dada produção de inputs).

A técnica DEA possibilita determinar a fronteira de produção e, consequentemente, as eficiências relativas de cada operador. Esta, ao contrário de outras técnicas de benchmarking (paramétricas), não necessita de uma especificação prévia para os pesos de cada input/ output, nem exige juízos à forma da função de produção, o que é comum nas metodologias paramétricas.

Outro aspecto relevante da metodologia relaciona-se com o facto de esta ser uma técnica fronteira, isto é, nas suas comparações, utilizar como referência as entidades extremas correspondentes às óptimas práticas e não o ajustamento médio, como acontece com as regressões estatísticas e com os indicadores de desempenho. A eficiência é estabelecida em relação a uma fronteira eficiente. Ao definir a fronteira, a técnica DEA possibilita identificar peers (best practices) para cada operador, bem como os seus valores-alvo (targets) para os diferentes inputs e outputs.

Charnes, Cooper e Rhodes (1978), ultrapassando o problema da programação fraccionária, efectuando um pequeno artifício, desenvolveram o chamado modelo CCR (suas iniciais) baseado em RCE.
Considerando minimização de inputs, admitindo que cada operador produz os outputs $y_{i}, i=1, \ldots, I$, a partir dos inputs $x_{j}, j=1, \ldots, J$, com os respectivos pesos $a_{i}$ e $b_{j}$ e que $M$ se refere ao número total de operadores, obtém-se a seguinte formulação:

$$
\begin{aligned}
& \operatorname{Max}: W_{k}=\sum_{i=1}^{I} a_{i} y_{i m} \\
& \text { s.a. } \\
& \sum_{j=1}^{J} b_{j} x_{j m} \leq \sum_{i=1}^{I} a_{i} y_{i m} \quad m=1, \ldots, k, \ldots, M \\
& \sum_{j=1}^{J} b_{j} x_{j k}=1 \\
& a_{i}, b_{j}>0 \quad i=1, \ldots, I ; j=1, \ldots, J
\end{aligned}
$$

Equação 1

A resolução do problema de programação linear (Equação 1) resultará em valores para cada $W_{k}$ entre zero e um, que correspondem à eficiência relativa de cada operador. Assim, se $W_{k}$ for igual a 1 significa que a entidade pratica um serviço eficiente em relação às restantes e caso $W_{k}$ seja menor que um, significa que existem outras entidades mais eficientes.

O modelo posteriormente desenvolvido por (BANKER; CHARNES; COOPER, 1984) contempla rendimentos variáveis à escala, adicionando ao modelo anterior a limitação do somatório dos pesos ser igual a 1 .

Se relacionarmos as eficiências técnicas obtidas por RCE (modelo CCR) com aquelas originárias em RVE (modelo BCC) as mesmas podem ser desagregadas em dois componentes, um devido à eficiência de escala e outro devido à eficiência técnica pura. Este resultado pode ser obtido mediante a aplicação dos modelos de DEA, admitindo RCE e RVE.

Caso exista diferença entre as duas eficiências técnicas obtidas para o mesmo operador, indica que existe ineficiência de escala do operador, e que pode ser calculada pelos resultados obtidos dos diferentes métodos. A eficiência de escala contabiliza o grau de economias verificado se o operador estivesse operando na escala óptima.

\section{Caso de estudo}

\section{Recolha de dados}

A presente investigação pretende avaliar a eficiência dos SRU portugueses. O estudo englobou as 29 entidades gestoras do sector que envolvem, sobretudo, o mercado secundário (tratamento dos resíduos), abrangendo a totalidade da população portuguesa continental. O ano de análise cingiu-se ao de 2005 tendo-se, no entanto, sempre comparado a informação considerada com a disponibilizada relativa ao ano de 2004 , para verificar a existência de eventuais incongruências.

A informação recolhida e utilizada, neste domínio, foi maioritariamente fornecida pelas entidades gestoras. Todavia, face a algumas 
dificuldades de recolha de informação, houve, em alguns casos, necessidade de recorrer a algumas simplificações, designadamente quando existiam diferentes actividades disponibilizadas pelas entidades gestoras (por exemplo, mercado terciário). Por fim, realçando o papel do Irar, foi possível cruzar informação dos documentos requeridos e, por conseguinte, tirar ilações sobre os valores mais susceptíveis de estarem incorrectos.

\section{Caracterização do modelo}

Adoptou-se uma orientação de minimização de inputs em virtude de, por um lado, as entidades gestoras terem de servir todos os utilizadores dos SRU e, por outro lado, de existir uma política de minimização de procura deste serviço. Não faria sentido optar por um modelo de maximização de outputs nem se justificaria o esforço adicional da utilização de modelos não orientados. Desta forma, a opção recaiu sobre a minimização de inputs (orientação input), dando uma maior relevância à manutenção (ou ao incremento) do nível de serviço prestado com a utilização mínima possível dos factores de produção (inputs)

O modelo aplicado compreende dois inputs (OPEX e CAPEX) e dois outputs para o serviço de resíduos, como já foi previamente referido. Em relação aos inputs considerou-se para o CAPEX os valores constantes nos relatórios de contas referentes a amortizações, provisões e juros. Considerou-se para o OPEX os restantes encargos, a saber os custos de mercadorias vendidas e matérias consumidas; os fornecimentos e serviços externos; o custo pessoal e outros custos. No domínio dos outputs produzidos foram utilizados os resíduos tratados em todo o sistema, incluindo resíduos industriais banais, e os resíduos reciclados

O modelo concebe ainda três factores explanatórios que influenciam, à partida, a eficiência dos SRU, designadamente, a densidade populacional existente na área de influência da entidade gestora, o produto interno bruto (PIB) per capita ao nível regional e a distância média às instalações de tratamento (aterros sanitários, centrais de compostagem e centrais de incineração).
Foram calculados vários modelos admitindo RCE (modelo CCR) e RVE (modelo BCC), bem como outras condicionantes, procurando uma melhor caracterização do ambiente de produção. Foi ainda empregue o modelo de ordem-m, que será discutido adiante, e a integração do tratamento do ambiente operacional, por meio da consideração de um segundo estágio, por intermédio de uma regressão Tobit.

\section{Resultados e discussâo}

\section{DEA}

A Figura 1 evidencia os valores da eficiência técnica e eficiência técnica pura do modelo para os SRU portugueses por operador.

Os níveis de ineficiência dos SRU portugueses foram relativamente significativos, para o ano de 2005, tendo em conta o resultado médio da eficiência técnica de 0,575. Em Portugal, os SRU têm um potencial de melhoria de eficiência técnica média de $42,5 \%$, da qual $15,1 \%$ correspondem apenas a ganhos de escala. Isto significa que, em média, cada operador pode reduzir em $42,5 \%$ os inputs consumidos (OPEX e CAPEX) produzindo a mesma quantidade de outputs, ou seja, de resíduos tratados e reciclados.

Conforme referido, se a escala fosse óptima, ou seja, se existissem RCE, os SRU consumiam menos 15,1\% dos inputs, para a mesma quantidade de outputs produzidos. Dos 29 operadores, 15 operadores apresentam rendimentos crescentes à escala, 12 operadores rendimentos decrescentes à escala e 2 RCE. Ao considerar a população servida e a quantidade de resíduos tratados para cada operador, o valor da eficiência técnica é superior, em virtude da compensação da eficiência de escala dos operadores mais populosos e que tratam uma maior quantidade de resíduos. Para o caso português foi possível aferir que os SRU detêm uma escala óptima de 300.000 habitantes.

Para os SRU portugueses (mercado secundário) e para o modelo RVE, as entidades gestoras 6 e 27 são as mais utilizadas como peers. A entidade gestora 6 é utilizada 17 vezes como peer e a entidade 27 é utilizada dez vezes. A importância que a entidade gestora 6 toma
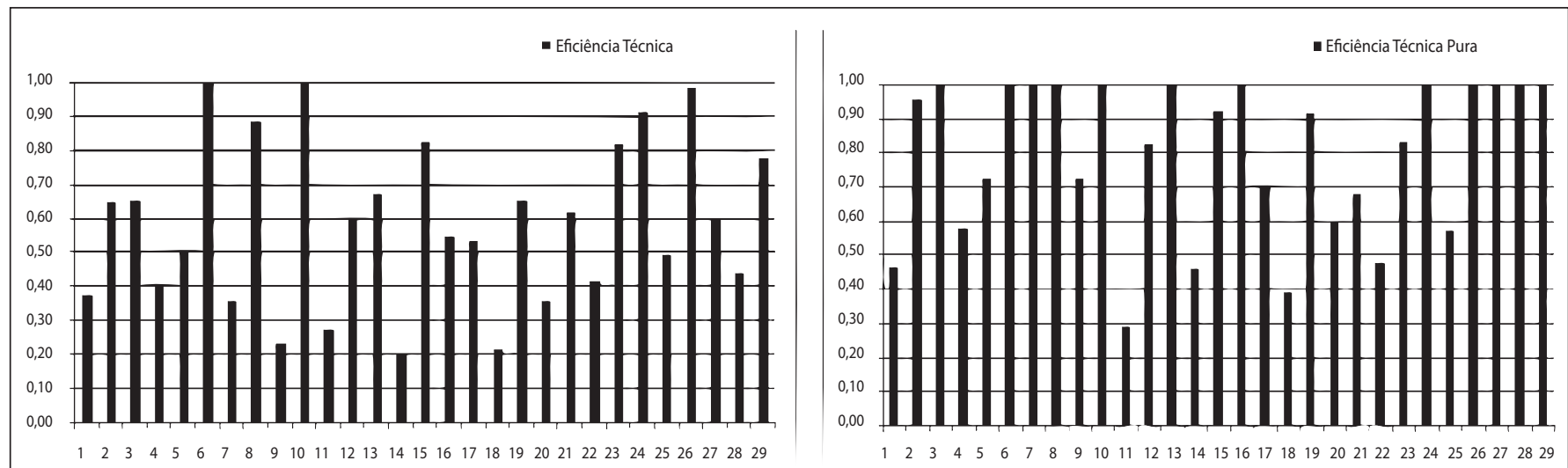

Figura 1 - Eficiência técnica e eficiência técnica pura por operador de SRU 
para as restantes é facilmente explicada pelas suas eficiências para o modelo adoptado. Deve ser efectuada uma análise futura a esta entidade para verificar se corresponde realmente a uma "melhor prática" ou se constitui um outlier.

\section{Ordem-m}

Como alternativa à técnica de fronteira não paramétrica utilizada, relativa à DEA, poderia ter sido utilizado o método de fronteira não paramétrico free disposal hull (FDH), cuja única diferença, em relação a (1), se prende com a substituição da restrição $a_{i} b_{j}>0$ por $a_{i}, b_{j}$ binárias. Contudo, os resultados daí obtidos, face ao número restrito de entidades gestoras em Portugal, ditaram muitas entidades gestoras dos SRU eficientes, o que de certa forma deturpa a realidade. Como tal, como primeiro procedimento optou-se por prevalecer o DEA face ao $\mathrm{FDH}$, no entanto o mesmo não acontece ao implementar o recente conceito de ordem-m, no qual com base no FDH, sendo teoricamente mais correcta (menos restritiva), são mensuradas novas eficiências.

Neste âmbito foi desenvolvido um estimador com base no expected minimum input frontier da ordem-m (CAZALS; FLORENS; SIMAR, 2002). Este conceito de ordem-m não impõe a convexidade à função produção e permite a presença de erro (apesar de ser expectável o valor de zero) nas avaliações orientadas para inputs. Um outro aspecto de maior relevância está associado à extrema sensibilidade da DEA à presença de outliers. Factor esse que possui muito menos influência na ordem-m. Além disso, a ordem-m tem a vantagem de necessitar de muitos menos informação (dados) do que a DEA.

As eficiências das entidades gestoras, obtidas pela ordem-m, surgem da comparação do consumo actual de inputs com o valor mínimo expectável de inputs consumidos, estabelecido através de $k$ (neste caso $k=200$ ) amostras de $m$ entidades gestoras, que produzem pelo menos tantos outputs como os SRU contemplados.

A determinação de $m$, amplamente discutida na literatura, é arbitrária, mas "a few values of $m$ could be used to guide the manager of the production unit to evaluate its own performance" (CAZALS; FLORENS; SIMAR, 2002). Este procedimento é desenvolvido mediante um processo iterativo que contempla vários valores de $m$ até ao correspondente que estabiliza o número de entidades supereficientes.

Através das eficiências obtidas é possível aferir que os respectivos valores inferiores a 1,0 indicam que o serviço se encontra a consumir mais que o mínimo expectável, enquanto as eficiências superiores a 1,0 dizem respeito às entidades gestoras que usam menos inputs do que o mínimo expectável. Este valor de mínimo expectável não é mais que a média dos inputs consumidos de cada $k$ amostras. A Figura 2 explana as eficiências, e a correspondente média, para cada entidade gestora da amostra e para quatro valores de $m$.

Apesar de existir uma relação inversa entre as eficiências da ordem-m e o parâmetro $m$, as tendências mantêm-se para os diferentes valores de $m$ contemplados. Em concordância com os valores obtidos através do DEA, as entidades com valores superiores a 1,0 são as eficientes e as entidades com os valores mais baixos são as mais ineficientes. Todavia, em casos especiais, como sucede para entidade gestora 6, carecem de alguma atenção em especial face ao valor de eficiência tão díspar da restante amostra.

Neste caso, para $m=5$, as entidades gestoras, em média, usam 77\% do total mínimo expectável, sendo que a eficiência média obtida da ordem-m foi de 1,29.

\section{Tratamento do ambiente operacional}

A prestação de um serviço, ou seja, a capacidade de transformar factores de produção, e os fins desejados são consideravelmente influenciados pela eficiência técnica dos operadores e também, em larga escala, pelo ambiente operacional que a caracteriza. Desta forma, os resultados dos modelos de DEA têm um valor limitado se não for tido em conta o meio ambiente e operacional, que caracteriza a prestação do serviço pelos operadores (FRIED; SCHMIDT; YAISAWARNG, 1999).

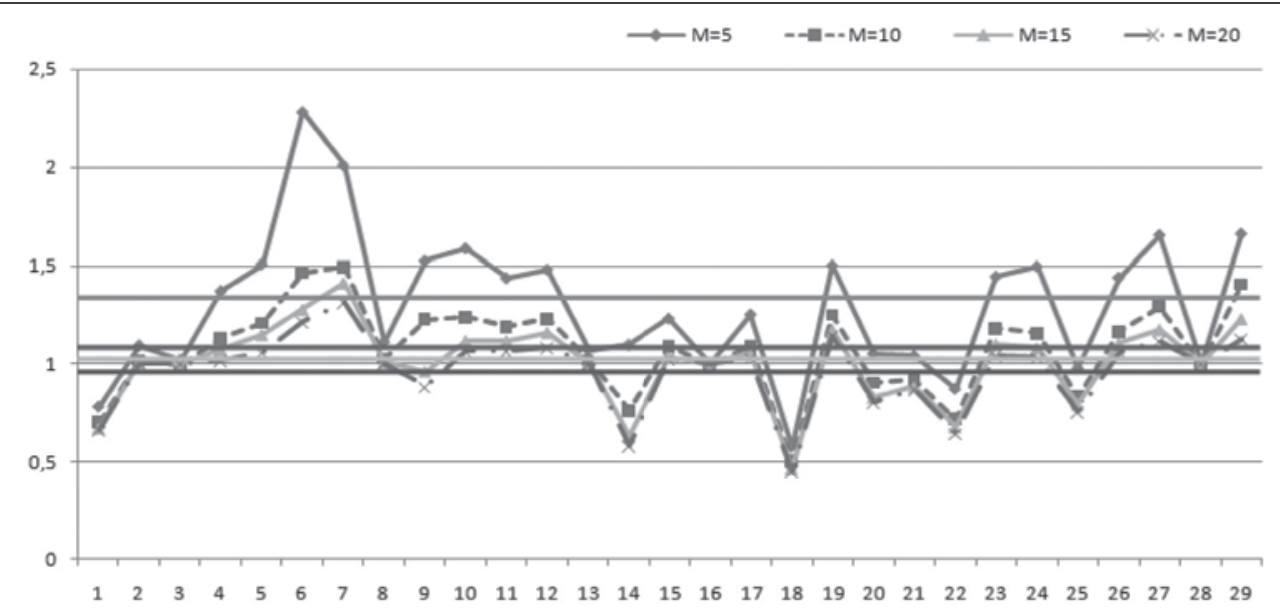

Figura 2 - Eficiências resultantes da ordem- $m$ para quatro valores diferentes de $m$ 
A metodologia bietápica representa um dos procedimentos mais adoptados para a integração do ambiente operacional na análise. Este processo, numa primeira fase, contempla a resolução da técnica DEA, sem os factores explanatórios. Posteriormente, numa segunda fase, consiste na aplicação de regressão aos resultados, na qual a eficiência é representada pela variável dependente e as variáveis independentes são, por conseguinte, os factores explanatórios. O sinal de cada factor explanatório indica a correspondente influência na eficiência e a sua importância, mediante testes estatísticos, podendo ser averiguada. $O$ segundo estágio corrige os valores obtidos no primeiro estágio, tendo em conta os factores explanatórios.

Não obstante a quantidade de operadores eficientes aconselhar, a fórmula de regressão adoptada pode ser uma ordinary least square (OLS) ou mesmo requerer a resolução do modelo de Tobit, em virtude do mesmo se adaptar melhor a dados truncados ou censurados (em um dos modelos DEA).

A densidade populacional, o PIB per capita, na área de abrangência das entidades gestoras, e a distância média ao local de tratamento (aterro sanitário, central de compostagem ou central de incineração) foram os referidos factores explanatórios contemplados. Será esperado que quanto maior for a densidade populacional e maior for o PIB per capita para as entidades gestoras maior será a sua eficiência. Por outro lado, quanto maior for a distância ao local de tratamento menor será a eficiência do operador.

Os resultados da regressão Tobit, obtidos com o software Lindep, permitem concluir que os coeficientes da regressão são positivos quer para densidade populacional quer para o PIB per capita e negativos para a distância ao aterro. No entanto, apenas o PIB per capita é estatisticamente significante a mais de $95 \%$ e para o modelo RVE.

O modelo de Tobit pretende ajustar as eficiências técnicas obtidas pela DEA (brutas), removendo a influência dos factores explanatórios. De acordo com a expressão anterior pode ser calculada a eficiência técnica corrigida. Valores superiores a 0 significam que o ambiente operacional tem um efeito positivo na eficiência, enquanto valores negativos ilustram um impacto negativo. Outra possibilidade de determinar as eficiências técnicas corrigidas é através do quociente entre o valor previsto da eficiência para os valores médios dos factores explanatórios e o valor obtido pela DEA. A relação entre estes dois valores fornece o valor da eficiência corrigido, tendo em consideração o mesmo ambiente operacional.

\section{Conclusões}

Os modelos desenvolvidos, admitindo RCE e RVE, permitiram concluir que os níveis de ineficiência dos operadores dos SRU portugueses para o ano de 2005 foram relativamente significativos. Em termos práticos, caso as entidades operassem de modo eficiente ocorreria uma redução dos custos superior a 100 milhões de euros.

O estudo efectuado permitiu aferir, de igual modo, que os sistemas detêm uma dimensão óptima na ordem dos 300.000 habitantes. Este resultado reflecte que caso um operador consiga aumentar a sua dimensão operacional até aos 300.000 utilizadores, diminuirá os seus custos marginais com a população, verificando-se o contrário na situação inversa (população superior a 300.000 habitantes).

A aplicação do modelo de ordem-m permitiu observar que, na amostra, poderiam existir outliers, sobretudo, a entidade gestora 6 . Este operador evidencia um valor de eficiência muito elevado, tendo em consideração a restante amostra, requerendo, por isso, cuidados especiais. Em média, as entidades gestoras dos SRU usam 77\% do total mínimo expectável.

Por último, estudou-se a influência do ambiente operacional na eficiência. Para os factores explanatórios integrados no modelo, designadamente a densidade populacional, o PIB per capita e a distância ao local de tratamento (os mais adoptados na literatura), verificou-se que apenas o PIB per capita era estatisticamente significante a $95 \%$ e para o modelo RVE. Além disso, constata-se que, como era esperado, o ambiente operacional tem uma influência significativa na eficiência dos operadores.

\section{Referências}

BANKER, R.D.; CHARNES, A.; COOPER, W.W. Some models for estimating technical and scale inefficiencies in data envelopment analysis. Management Science, v. 30, n. 9, p. 1078-92, 1984.

BENITO, B.; BASTIDA, F.; GARCÍA, J.A. The determinants of efficiency in municipal governments. Murcia: Fundación Séneca of the Autonomous Community of the Region of Murcia, 2005.

BOSCH, R.N.; PEDRAJA, C.F.; SUÁREZ, J.P. The efficiency of refuse collection services in Spanish municipalities: do non-controllable variables matter? Document de Treball. Barcelona: Institut d'Economia de Barcelona, 2001
CAZALS, C.; FLORENS, J.P.; SIMAR, L. Nonparametric frontier estimation: a robust approach. Journal of econometrics, v. 106, n. 1, p. $1-25,2002$

CHARNES, A.; COOPER, W.W.; RHODES, E. Measuring the efficiency of decision making units. European Journal of Operational Research, v. 2, n. 6, p. 429-44, 1978.

DISTEXHE, V. L'efficacité productive des services d'enlévement des immondices en Wallonie. Cahiers Economiques de Bruxelles, v. 34, n. 137, p. 119-38, 1993. 
FRIED, H.O.; SCHMIDT, S.S.; YAISAWARNG, S. Incorporating the operating environment into a nonparametric measure of technical efficiency. Journal of Productivity Analysis, v. 12, n. 3, p. 249-67, 1999.

IRAR (2006). Relatório Anual dos Serviços de Água e de Resíduos em Portugal. Instituto Regulador de Águas e Resíduos, Lisboa.

MARQUES, R. Avaliação e medição de eficiência de unidades organizatórias através do método fronteira não paramétrico de data envelopment analysis (DEA). Apontamentos das Aulas, (Mestrado em Investigação Operacional e Engenharia de Sistemas) - Instituto Superior Técnico, Lisboa, 2006A.

A yardstick competition model for Portuguese water and sewerage services regulation. Utilities Policy. v. 14, n. 3, p. 175-184, $2006 \mathrm{~B}$. 2005

Regulação de serviços públicos. Lisboa: Edições Sílabo,

SANCHEZ, I.M. Efficiency of solid waste collection in Spain. In: III International Conference on waste management and the environment. Wit press, 2006. p. 593-601.

TEIXEIRA, C.; NEVES, E. Gestão de resíduos - indicadores de desempenho de sistemas. Sector Editorial dos SDE, Série Didáctica Ciências Aplicadas, 2007. Universidade de Vila Real, Portugal.

VILARDELL, I.; RIERA, I. L'eficiencia en l'actuació de les administracions municipals: una avaluació del servei de recollida de residus sólids urbans. Revista Económica de Catalunya, n. 11, p. 19-33, 1989. 